\title{
In collaboration with the Canadian Critical Care Society, the Canadian Journal of Anesthesia is proud to publish the best posters presented at the 2005 Toronto Critical Care Medicine Symposium
}

The Toronto Critical Care Medicine Symposium has matured to become one of the leading international meetings in Critical Care Medicine. In 2005, fifty-six reports of clinical and laboratory investigations were presented, covering all aspects of critical care medicine. From these papers, a panel of the Canadian Critical Care Society selected the best posters, which the Canadian Journal of Anesthesia is proud to publish.

The King Award is presented annually by the Canadian Critical Care Society for the best oral presentation by a resident. This award is named after Dr Garner King, who was past Professor and Head of the Department of Medicine at the University of Alberta. Dr King trained many of the first generations of critical care physicians in Canada, and also many from abroad. He was the second president of the Canadian Critical Care Society (19781980).

\section{Toronto Critical Care Medicine Symposium Toronto, Ontario} October 26 - October 28, 2005 


\section{1st. prize and King Award}

Name: Alexis F. Turgeon

Position: Clinical and Research Fellow

Professional Initials: MD MSc FRCPC

Department: Critical Care Medicine

Institution: University of Ottawa, The Ottawa Hospital - General Campus

Address: 501 Smyth Road, BOX 207

City: Ottawa

Province: Ontario

Country: Canada

Postal Code: KIH 8L6

E-mail: alexisturgeon@yahoo.ca

Co Authors Name: Brian Hutton, Dean Fergusson, Paul C. Hébert, Lauralyn McIntyre

Institution Affiliation: OHRI - Centre for Transfusion and Critical Care Research

\section{EFFECT OF INTRAVENOUS IMMUNOGLOBULINS IN CRITICALLY ILL ADULTS WITH SEPSIS: A META-ANALYSIS}

Alexis F. Turgeon MD MSc FRCPC, Brian Hutton MSc, Dean Fergusson MHA PhD, Paul C. Hébert MD MSc FRCPC, Lauralyn McIntyre MD MSc FRCPC, for the Centre for Transfusion and Critical Care Research and the Critical Care Medicine Program, University of Ottawa, Ottawa, Canada.

Introduction: Intravenous immunoglobulin therapy has been proposed as an adjuvant treatment in sepsis. However, the benefit of the therapy remains unclear and its use is not currently recommended. This systematic review evaluated the effect of polyclonal in immunoglobulin therapy on mortality in critically ill adult patients with sepsis.

Methods: A systematic search strategy was applied to Medline (1966-September 2005) and the Cochrane Register of Controlled Trials (September 2005) to identify all randomized controlled trials of polyclonal iv immunoglobulin therapy with a placebo comparison or no intervention during the course of sepsis, severe sepsis or septic shock in critically ill adult patients. Abstracts and book chapters were included, and no restriction was placed on language of publication. The primary endpoint was all-cause mortality. Review of citations retrieved from the electronic search, methodological assessment and data extraction were independently performed by two investigators. References of all identified trials were reviewed for additional studies. Authors of trials were contacted to provide additional clinical data or information on methodology when unclear.

Results: Eighteen trials $(n=2,127)$ met eligibility criteria and were included in the analysis. Polyclonal $i v$ immunoglobulin therapy was associated with an overall survival benefit of $32 \%$ (risk ratio $[R R]=0.68,95 \%$ confidence interval $[\mathrm{CI}], 0.55-0.84)$ compared to placebo or no intervention. The benefit of the therapy improved when only published data and peer-reviewed trials were analyzed $(\mathrm{RR}=0.66,95 \% \mathrm{CI}, 0.49-0.85),(13$ trials, $n=1287)$ and when only trials designed with a placebo group were included $(\mathrm{RR}=0.61,95 \% \mathrm{CI}, 0.40-0.93),(7$ trials, $n$ $=896)$. From the three high-quality trials $(n=701)$ including one large unpublished trial trending toward negative, pooled results showed a trend for a survival benefit $(R R=0.78,95 \% \mathrm{CI}, 0.43-1.40)$. No major side effect attributable to $i v$ immunoglobulin therapy was reported in any of the trials.

Conclusion: We observed a survival benefit from all summary estimates of studies with the use of polyclonal iv immunoglobulin therapy in sepsis compared to placebo or no intervention. Despite most studies being conducted before the current standard of therapy for sepsis was established, it should be considered as a potential adjuvant therapy. However, polyclonal iv immunoglobulin therapy should be further studied in well-defined high-risk populations with the current standard of therapy before its systematic use is recommended. 